\title{
Tres metáforas metafísicas de la condición humana: El náufrago, el extranjero, el viajero ${ }^{1}$
}

\author{
Ramón Rodríguez \\ Universidad Complutense. Madrid, España. \\ ramon@filos.ucm.es
}

Si la filosofía es la única actividad humana en que no solo es legítimo, sino obligado comportarse con un radicalismo absoluto, la apreciación y el valor filosófico de esta se mide por el nivel de su radicalismo, por su capacidad de cavar más hondo que las que la precedieron y de sacar a la luz aspectos de las raíces nunca vistos o, incluso, la textura del terreno del que se alimentan. La filosofía del siglo $\mathrm{xx}$ ha seguido de forma incansable ese camino de radicalismo, fiel a la enseñanza de Husserl en la Filosofía como ciencia estricta: "la filosofía, según su propia esencia, es ciencia de los verdaderos principios, de los orígenes, de los rizómata pánton" (71). Lo que yo quisiera mostrarles a ustedes es que ese afán de radicalidad se sirve inevitablemente, como ya nos enseñó Platón, de metáforas, ante la ausencia de conceptos precisos y manejables que den cuenta del nivel radical alcanzado.

Blumenberg ha acuñado la acertada expresión de "metáforas absolutas" para plantear la hipótesis de que ciertos elementos básicos del lenguaje filosófico contienen transferencias de sentido que no se dejan reconducir hacia el concepto nítido, que no admiten ser convertidas en la terminología conceptual al uso de la ciencia (Paradigmas 44). El nombre de absolutas "sólo significa que muestran su resistencia a la pretensión terminológica, que no se pueden resolver en conceptualidad" (47). No puede extrañarnos esa resistencia cuando Blumenberg señala en otro momento que "las metáforas absolutas 'responden' a preguntas aparentemente ingenuas, incontestables por principio, cuya relevancia radica en que no son eliminables, porque nosotros no las planteamos, sino que nos las encontramos como ya planteadas en el fondo de nuestra existencia" (63). Esta peculiaridad de su campo de aplicación contribuye sin duda a redoblar, en

1 Este documento es el resultado de la clase magistral del profesor Ramón Rodríguez dictada en el inicio del año académico de la Facultad de Filosofía, Pontificia Universidad Católica de Chile, a comienzos de abril de 2019. 
un nuevo giro, el carácter absoluto de la metáfora, pues, ciertamente, esta encuentra su sentido en la problematicidad o perplejidad inherentes a aquel tipo de situaciones que pueden llamarse fundamentales, porque nos encontramos siempre ya en ellas, porque nos vienen ya dadas antes de que ninguna reflexión las tome por objeto ("el fondo de nuestra existencia"). La metáfora es absoluta porque la pregunta a la que responde emana de una situación "absoluta", originaria, que da sentido al preguntar que la encara y a los conceptos, metafóricos, que articulan la respuesta, sin dejarse sin embargo domeñar por ellos, sin transparecer en ellos de manera satisfactoria.

La filosofía del siglo xx ha usado al menos tres viejísimas metáforas -el náufrago, el extranjero y el viajero- para intentar con ellas pensar el plano último de inteligibilidad, el ámbito originario más atrás del cual no cabe ir. Se trata de utilizar una vieja imagen de la condición humana para un problema típicamente moderno, el del nivel trascendental último, el de aquel estrato irrebasable al que llega una reflexión que se pregunta por las condiciones de posibilidad, en este caso ontológicas, de la situación fáctica, real, del vivir humano. Conviene, por eso, apreciar bien cuál es el problema a cuyo socorro las metáforas acuden. Se trata de comprender una situación que, por ser absoluta, inicial, no se ofrece en un horizonte de sentido, en una trama de experiencia determinada que permita abordarla; carecemos, por así decir, de la guía previa que supone saber cuál es el horizonte en que podemos colocarla; por ello mismo, tampoco puede ser situada en un ámbito común de comparación con otros contextos de la experiencia que funde la semejanza metafórica. Solo cabe realizar una comparación, tácita y necesariamente arbitraria, entre una experiencia humana concreta, que se estima especialmente significativa, y la "realidad radical", para inmediatamente amputar a la primera todo el contexto vital que la hace inteligible. Pero en el fondo esa tácita comparación no es propiamente tal: la situación originaria que se pretende mostrar no está dada como un objeto al que se pudiera mirar y ver en él la igualdad de relación, la analogía que guarda con la experiencia de la que parte la traslación de sentido. Solo tenemos esta, la experiencia, y desde ella, con la sola fuerza de su imagen, hemos de acceder al sentido de la "realidad radical"; la amputación de todo el contexto de la experiencia base es el recurso que otorga a la metáfora todo su poder sugeridor, toda su capacidad de situarnos en un nivel originario, pero también lo que plantea todas las dificultades de interpretación. La metáfora cumple así una doble función: el modo metódico de acceso al nivel último, pero también lo que proporciona, mediante su análisis, los rasgos estructurales, la consistencia, de la situación originaria. Veámoslo con la primera de las metáforas, la del naufragio.

Resulta muy indicativo de las dificultades del pensamiento en lengua española para abrirse paso en el ámbito internacional que Blumenberg no cite en su bello libro, Naufragio con espectador, al filósofo que sin ninguna duda ha utilizado con más reiteración y profundidad la metáfora del naufragio: Ortega y Gasset. Ortega utiliza la metáfora claramente en el marco de lo que Blumenberg llama el "giro existencial" (Naufragio 28), donde los antecedentes del naufragio (el puerto, la calidad de la nave, 
la travesía hacia otro puerto y, sobre todo, un espectador ajeno que mira desde fuera la totalidad de la situación) desaparecen progresivamente: solo queda la situación de naufragio pura y simple, vivida desde dentro por un náufrago que se encuentra en ella sin referencias previas, que ha "olvidado" por tanto la situación anterior, una pérdida de conciencia que Ortega subraya con otra imagen, la del personaje que, dormido, es llevado al escenario de un teatro y, despertado de un empujón, se ve forzado a improvisar ante el público (Obras completas XII 35). Esta carencia de referencias previas que retuerce la imagen cotidiana del naufragio es lo que la habilita para dar a pensar la realidad radical:

La vida no es el sujeto solo, sino su enfronte con lo demás, con el terrible y absoluto otro que es el mundo donde al vivir nos encontramos náufragos. No creo que haya imagen más adecuada de la vida que ésta del naufragio. Porque no se trata de que a nuestra vida le acontezca un día u otro naufragar, sino que ella misma es desde luego y siempre hallarse inmerso en un elemento negativo, que por sí mismo no nos lleva, sino al contrario, nos anula (V 420).

Pidiendo un Goethe desde dentro subraya en el mismo sentido: "La vida es en sí misma y siempre un naufragio" (IV 397). "En sí misma y siempre", la doble expresión muestra con absoluta sencillez lo que Ortega quiere darnos a entender con la metáfora: que la condición ontológica básica de la vida solo se deja aprehender por medio de la traslación de sentido que proporciona el naufragio. Este revela lo que la vida propiamente es, anuncia su posible estructura y lo hace como una situación originaria que no cabe derivar de otras instancias. Este es el sentido del "siempre": no que la vida posea rasgos idénticos que se repitan en toda ocasión, sino que solo cabe entenderla desde una situación inicial, que es originaria precisamente porque no remite a un momento histórico, sino porque se deja sentir haciendo inteligibles nuestras situaciones reales; lo originario se hace sentir, se deja ver y esa visibilidad es la que proporciona la metáfora.

Si cortamos todas las condiciones antecedentes que hacen comprensible la imagen habitual del naufragio, tal como hace Ortega, que en múltiples ocasiones la introduce como forma de subrayar el puro hecho de estar arrojados en la vida, al modo de la Geworfenheit heideggeriana -"náufragos en un orbe impremeditado"-, la situación misma de naufragio propone una estructura inteligible para comprender la vida en su carácter de raíz, que es menester destacar.

Ante todo, la situación por sí misma muestra una excepcionalidad y una extrañeza básicas: el náufrago, el hombre que bracea, no se encuentra en su ambiente, está fuera de sitio, el agua sobre la que trata de mantenerse a flote no es su lugar propio; por ello, la idea de que se trata de un momento excepcional, que no puede ser la regla de su vida, se abre paso. Sin embargo, justamente esa excepcionalidad, ese aparente carácter episódico, es lo que rompe y deshace la metáfora; ya Blumenberg hizo notar que el hombre "que conduce su vida y levanta sus instituciones sobre tierra firme, prefiere 
concebir el movimiento de su existencia mediante la metafórica de la navegación arriesgada" (Naufragio 13). El naufragio como metáfora absoluta, como expresión de una situación inicial lleva esa inversión al extremo: lo que solo puede concebirse como excepcional se convierte en condición ontológica última, en la raíz misma de lo que somos. De esta inversión surgen, como decía antes, las dificultades de entender a fondo el significado del naufragio como metáfora de la realidad radical.

Todo el aprovechamiento metafísico del naufragio se teje sobre esa excepcionalidad primaria, sobre el choque que produce el que una situación, cuya inteligibilidad habitual depende de un contexto vital más amplio (el de la navegación), haya de ser entendida sin contexto, como origen absoluto.

En efecto: de un lado, el naufragio destaca -y así lo hace Ortega en la gran mayoría de los textos- precisamente la inicial extrañeza del medio, lo profundamente ajeno del ambiente en el que se encuentra el náufrago. La otredad esencial del medio es lo que primero impone la imagen del náufrago: "la vida es darme cuenta, enterarme de que estoy sumergido, náufrago en un elemento extraño a mí” (XII 47); la absoluta heterogeneidad de la circunstancia, su extrañeza radical, incluso su hostilidad, es lo que define el ámbito en el que se realiza la vida: "vivir es ejecutar mi esencia o lo que yo soy, fuera de mí; fuera de mí, se entiende fuera de mi esencia, en lo que no es mi esencia, en un elemento extraño a mi ser" (XII 57). Como es bien sabido esa extrañeza básica coincide con el núcleo significativo del término existir, el absoluto estar fuera de.

Pero, a su vez, la extrañeza de la circunstancia revela la peculiar forma de ser del náufrago: dado que aquella le es originariamente extraña, el ser que se encuentra, no menos originariamente, teniendo que existir en ella está afectado en su, digamos, dotación ontológica de una inadaptación de principio, de una no-coincidencia con su medio. Este carácter, que se define como negativo por relación a la circunstancia, es sin embargo definitorio de lo que el náufrago es en sentido positivo, preside todo lo que él puede ver y decir de sí; lo que en la Meditación de la técnica Ortega llama "el programa extranatural del hombre" (V 346), su afán de ser, su ser pura pretensión de ser, que es lo único que propiamente puede predicarse de él, solo es posible entenderla a partir del extrañamiento originario que define la relación hombre-circunstancia. Con extraordinaria agudeza señala Ortega que, en la coincidencia absoluta con la circunstancia, que suponemos propia del animal, no tiene sentido hablar de necesidades: en un régimen de coincidencia, de perfecta adaptación, lo que llamamos necesidades (alimentarse, calentarse, guarecerse) no son tales, no pueden aparecer como tales, pues no podrían ser sentidas como imposición externa, como algo con lo que tengo que contar para hacer otra cosa que lo que ellas marcan. Algo es necesario justo cuando no puede por sí mismo llenar la totalidad de la existencia de quien lo necesita y solo por eso aparece para esta como algo impuesto, constrictivo. El animal puede no tener inmediatamente en su entorno lo que "necesita" y tiene que agenciárselo, pero su vivir consiste en eso y carece por ello de ese carácter de carga, de fardo que hay que arrastrar, que es lo que las necesidades que llamamos elementales suponen para el hombre. 
¿Por qué entonces no hacer de la metáfora del extranjero, que Ortega también utiliza en múltiples ocasiones en este contexto, la metáfora más expresiva de la radicalidad de la vida?

Aventuremos una respuesta: porque la metáfora del extranjero, que solo expresa la extrañeza originaria sobre la que reposa la situación entera de naufragio, no recoge un momento decisivo de la vida que el naufragio manifiesta con no menor evidencia: que la extrañeza del medio es a la vez y sin separación posible esfuerzo por sostenerse a flote, movimiento de braceo que se dispara sin reflexión alguna sobre lo extravagante de la situación. Es el heroísmo del náufrago, la desesperada lucha por sostenerse en el mar sin orillas, lo que atrae de manera constante la atención de Ortega. Que ese esfuerzo es un ingrediente originario de la situación no cabe la menor duda; pero es que además pone de relieve lo más radical de la vida humana en cuanto que esta es un ineludible hacer, un quehacer permanente e inagotable para sostenerse en el mundo. Pero lo que importa ahora subrayar es que el carácter originario del esfuerzo natatorio imprime un sello especial a la primitiva extranjería de la condición humana, pues hace que la circunstancia aparezca con una doble faz: sin duda sigue siendo por principio ajena, no coincidente, pero no hasta el punto de aniquilar sin remedio la vida en él; el mundo se ofrece entonces como aquello en lo que nos hundimos, pero en lo que, con un movimiento incesante, podemos mantenernos a flote. El medio líquido no es ciertamente el terreno propio de la vida humana, pero esta no es imposible en él; no es un vacío total, sino que, a pesar de su escasa densidad, ofrece alguna resistencia al movimiento del cuerpo, que es paradójicamente lo que permite la supervivencia en él. El sentimiento de zozobra por el hundimiento siempre posible puja con la alegría por la eficacia del esfuerzo, sin que pueda llegar estructuralmente un momento que deshaga la esencial ambivalencia de la situación. Y es ese esfuerzo natatorio del náufrago el que produce técnica y cultura, el que instituye mundo, un espacio habitable en el que mantener la vida y en el que saber a qué atenerse. En un sentido esencial el mundo así fabricado como respuesta a la inseguridad de la circunstancia es, frente a esta, un espacio que por primera vez puede ser calificado de "nuestro", porque el sentido que lo conforma es obra nuestra, producto de lo que la acción humana ha puesto trabajosamente en ella. Frente a la extranjería esencial de la circunstancia, que es la realidad primaria o auténtica, esos mundos son íntimos, cercanos, propios. La extrañeza de la circunstancia se torna entonces lugar acogedor, entorno cálido en el que encontrarse "en casa".

Pero la fuerza de la metáfora del naufragio, su nivel ontológico radical, se muestra en que el mundo cultural instituido por el esfuerzo del náufrago no tapona por completo la zozobra originaria, no logra hacerla desaparecer en una especie de olvido olvidado. Ortega tiende a interpretar las grandes crisis históricas, los momentos en que los espacios de duda y sinsentido crecen sin medida dentro del ámbito global de creencias, como situaciones en que la vida humana es devuelta a su condición originaria, como momentos de desorientación y agobio pronunciados, en las que emerge de nuevo la imagen del náufrago. 
Es entonces donde cobra sentido la segunda metáfora, el extranjero, la inhospitalidad, la Unheimlichkeit heideggeriana, pues ella apunta justamente a la ruptura del entorno acogedor, deshace los lazos e intereses que nos ligan al mundo y muestra la extrañeza originaria de la condición humana. ¿Cuál es entonces su relación con el naufragio? Ortega, ya lo he mencionado, no la acepta como metáfora última porque no deja ver el esencial esfuerzo creador del náufrago, solo la extrañeza de la circunstancia. ¿Pero es esto realmente así? ¿Cómo podemos pensar la aspiración de ambas metáforas al máximo nivel de radicalidad? ¿Son incompatibles?

Recapitulemos brevemente. El naufragio subraya que la extrañeza de la circunstancia aparece a una con el braceo salvador, que surge simultáneamente con ella. Ese es el momento que define propiamente lo que es el naufragio en su significación ontológica. No hay un instante en que la vida pudiera sorprenderse a sí misma antes de esa tensión por sostenerse y por eso, correlativamente, la extrañeza del entorno aparece como tal en el esfuerzo y solo en él. Ambos momentos son igualmente originarios y no cabe asomarse por detrás de esa estructura más que de manera ficticia, es decir, suponiéndola en alguno de sus elementos. Tal es, me parece, la posición firme de Ortega en cuanto al nivel metafísico-trascendental último. Desde ella es evidente que la Unheimlichkeit no puede ser lo que es en palabras del Heidegger de Ser y tiempo: "El no estar en casa debe ser concebido ontológico-existencialmente como el fenómeno más originario" (Sein und Zeit 189).

Pero miremos de nuevo hacia la situación radical del naufragio. Como ya sabemos, implica un extrañamiento de la circunstancia, un estar literalmente fuera de sitio, sin el que el naufragio carece de sentido. Ese extrañamiento, dado que en la metáfora es pensado como originario, implica en el náufrago una inadaptación radical, una imposibilidad básica de coincidir con el medio al que se ve abocado, de estar ajustado a él. Ortega no ha dejado nunca de reconocerlo y en múltiples ocasiones señala que "el hombre está a nativitate extrañado del mundo". Pero no ha creído necesario seguir pensando ese extrañamiento de la situación de naufragio hacia atrás, hacia lo que la negatividad de la no-coincidencia implica, sino hacia delante, hacia lo que ella inmediatamente dispara: el movimiento natatorio de salvación. Es en este donde, para Ortega, cobra todo su sentido el extrañamiento del mundo. Pero la in-adaptación, la in-digencia radical del náufrago, que no desaparece nunca, tiene por sí misma un extraordinario poder de relevación; pues esa negatividad con que la expresamos, precisamente porque significa que se sustrae a toda determinación por ajuste con el medio, dibuja la apertura de un espacio indeterminado al que el náufrago está correlativa e ineludiblemente adscrito. Esa referencia insoslayable a un ámbito de indeterminación se concreta en un medio, el agua marina del naufragio, pero no se identifica con ella: podría ser cualquier otro y el ser originariamente inadaptado seguiría viviendo en esa inadaptación. Pues bien, ese ámbito abierto de indeterminación, que el desajuste ontológico del náufrago lleva consigo y que forzosamente ha de concretarse en un medio sin poder nunca identificarse con él, es lo que constituye la 
Unheimlichkeit constitutiva, el originario no estar en casa. Lo desazonador es que ese ámbito, cuando aparece como tal, cosa que como es bien sabido acontece en el temple de la angustia, rompe toda adscripción acogedora a un mundo determinado, deshace toda conformidad permanente en él. Fenomenológicamente el "estar como en casa" precede a la Unheimlichkeit, pero ontológicamente esta es más originaria. Ciertamente la desazón aparece así (des-sazón) por contraste con lo sazonado del mundo en el que hemos logrado acomodarnos, pero no consiste en la mera contraposición a este ni es el aspecto inhóspito o negativo del mundo que convive a su lado. Lo que revela es algo más que eso: que el náufrago existe trascendiendo toda determinación, estando más allá de estas o aquellas facilidades y dificultades y de su propio hacer con ellas, y que es justamente esa apertura que el "más allá" del trascender mienta, lo que permite aparecer lo determinado del mundo, la balsa que nos fabricamos y las dificultades que vencemos. Estar fijado a ese ámbito que, pensado desde la indeterminación e inadaptación, Heidegger llamó en principio la nada (la nada en cuanto negación y desasimiento de los entes, pero que no es otra cosa que el espacio abierto del $\operatorname{ser}^{2}$ ) caracteriza a ese ser cuya condición es el naufragio y que por eso puede ser llamado Da-sein: ser en ese "aquí" abierto.

Pues bien, a mi entender, ese carácter dinámico del trascender, del estar más allá de toda determinación, implícito en la inadaptación constitutiva, es lo que subraya la tercera metáfora, el viajero, otra imagen clásica de la vida humana, ahora dotada de carácter absoluto. Permítanme que deje la palabra a Kafka, que ha expresado mejor que nadie la profundidad de esa vieja imagen. Se trata de un brevísimo relato que Max Brod tituló Der Aufbruch (La partida), pero que en el cuaderno de Kafka carece de título:

Ordené sacar el caballo de la cuadra. El criado no me comprendió. Fui yo mismo a la cuadra, ensillé mi caballo y monté. Oí a lo lejos el sonido de una trompeta, le pregunté qué significaba eso. Él no sabía nada, no había oído nada. Delante del portón me detuvo y preguntó. “¿Adónde vas, señor?”. “No lo sé, sólo quiero irme de aquí, irme de aquí. Marcharme siempre, sólo así puedo alcanzar mi meta”. “¿Así que conoces tu meta?”, preguntó. “Sí -respondí-, ya lo he dicho: 'Irme-de-aquî, ésa es mi meta" [Weg von hier, das ist mein Ziel]. "No has hecho provisión de víveres", dijo. "No me hace falta-dije-, el viaje es tan largo que moriré de hambre si no me dan algo por el camino. No hay provisiones que me salven. Afortunadamente, es un viaje verdaderamente inmenso" (Kafka 246).

El breve relato de Kafka, que merecería un largo comentario, deja completamente al desnudo la vieja metáfora del viajero, convirtiéndola en una rigurosa metáfora metafísica: hay una ausencia total de contexto, nada se sabe de las circunstancias del

2 Bastaría analizar, para no pasar al Heidegger posterior, el concepto de trascendencia en Qué es metafísica y en De la esencia del fundamento para ver que la enfática afirmación "la nada, como lo otro del ente, es el velo del ser" (GA $9312)$ está ya presente en el análisis de Ser y tiempo. 
viajero ni del porqué de su viaje; el entorno, el mundo compartido, es profundamente asignificativo: el criado no oye ni entiende nada y no puede por tanto responder a los requerimientos del viajero. Todo da a entender la soledad radical de este, que se encuentra remitido completamente a sí mismo, sin delegación posible: él mismo tiene que buscar y ensillar su caballo. Tan solo el sonido de una trompeta, que solo el viajero oye, introduce un significado, da a entender algo, tal vez una llamada para partir, un reclamo de salida. Pero lo más decisivo es sin duda la identidad entre el movimiento de salida y la meta, pues con ella se muestra no solo que la meta es inmanente al movimiento, sino que la salida misma es la meta, que el movimiento no se inicia por el reclamo de un objetivo determinado, sino que surge a partir de sí mismo. Es la espontaneidad del movimiento lo que posibilita la propuesta de metas, la adopción de fines. Solo un ser que es salida de sí, que es in-quietud originaria, puede proponerse metas. Y para ese viaje metafísico, raíz de todo viaje, no hay ni puede haber previsiones ni provisiones. Es la salida de sí, el camino siempre por hacer, el que funda toda previsión, lo que obliga a prever medios y fines, a hacer planes y preparar conductas.

La originariedad del movimiento de salida sin meta determinada supone un ámbito abierto, un espacio ignoto de posible tránsito, hacia el que el viajero necesariamente se encamina. Ese espacio que se abre puede y debe entenderse como exterior porque es completamente externo a lo que quiera que fuese la vida anterior del viajero, de la que nada sabemos. Representa una exterioridad pura, no en referencia al propio movimiento, sino respecto de la identidad previa del viajero, que es claramente dejada atrás sin huella alguna y que con ello se expone a la intemperie más completa. ${ }^{3}$ Como recalcaba Rafael Sánchez Ferlosio, al que querría dedicar aquí un emocionado recuerdo tras su reciente fallecimiento, el jinete "ya se ha puesto en camino y aún no sabe si va; lo que sí sabe, en cambio, perfectamente bien es que se va" (279). El misterioso sonido de la trompeta puede entonces indicar una llamada a emprender esa salida de sí hacia el horizonte indeterminado y abierto, pero una llamada -si es que es tal- que es a su vez indeterminada, que deja en el aire si hay una instancia apelante o si es el símbolo de ese tirón hacia fuera que nos saca de nosotros mismos y que tan bien representa la irrupción de una llamada.

La radicación en el ámbito abierto de indeterminación que marca la metáfora del extranjero y que la metáfora del viajero precisa como movimiento de salida de sí que trasciende toda determinación no altera la situación de naufragio, que sigue siendo la misma, ni mucho menos la sustituye por otra. Las "metáforas absolutas" de la inhospitalidad y del viaje no proponen, es importante verlo, una alternativa al

3 Es este aspecto lo que más aleja a Kafka del arquetipo del viaje clásico representado por la Odisea. No hay en la salida del viajero ninguna referencia al hogar perdido, la menor nostalgia de lo que se deja atrás, sino un puro y enfático deseo de salir. La ausencia completa de meta excluye toda Îtaca, pero excluye aún más toda forma de retorno, al que claramente se opone la idea central del relato. En cambio, hay una cierta cercanía con la idea bíblica del viaje, si por tal entendemos el que emprende Abrahán hacia la tierra prometida, pues la llamada de Yahvé es a ponerse en marcha "hacia la tierra que te mostraré" (“Génesis" 12), que, si bien supone una meta, es completamente indeterminada y sitúa al viajero ante un espacio completamente abierto. 
naufragio porque no ofrecen una nueva situación originaria que contraponerle. Tan solo muestran que es posible seguir pensando el naufragio en esa dirección hacia abajo, en esa dimensión de profundidad, en que consiste el progreso en filosofía. Y es este camino hacia las raíces, pero también la interna coherencia de la metafísica del siglo $\mathrm{xx}$, en su ancha corriente fenomenológica, lo que he querido destacar ante ustedes.

\section{Referencias}

Blumenberg, Hans. Paradigmas para una metaforología. Madrid, Trotta, 2003. ---. Naufragio con espectador. Madrid, Visor, 1995.

“Génesis". Nueva Biblia Española. Madrid, Cristiandad, 1975.

Heidegger, Martin. Sein und Zeit, 12a ed. Tübingen, Niemeyer, 1972.

---. Gesamtausgabe (GA) 9. Frankfurt, Klostermann, 1976.

Husserl, Edmund. Philosophie als strenge Wissenschaft. Frankfurt, Klostermann, 1981.

Kafka, Franz. "Fragmentos de cuadernos y hojas sueltas". Carta al padre y otros escritos.

Trad. Carmen Gauger. Madrid, Alianza, 2014.

Ortega y Gasset, José. Obras completas. Madrid, Revista de Occidente, 1947-1969.

Sánchez Ferlosio, Rafael. La homilía del ratón. Madrid, El País, 1986. 